\title{
Video Article \\ Induction and Testing of Hypoxia in Cell Culture
}

\author{
Danli Wu ${ }^{1}$, Patricia Yotnda \\ ${ }^{1}$ Center for Cell and Gene Therapy, Baylor College of Medicine
}

Correspondence to: Patricia Yotnda at pyotnda@bcm.edu

URL: https://www.jove.com/video/2899

DOI: doi:10.3791/2899

Keywords: Cell Biology, Issue 54, mammalian cell, hypoxia, anoxia, hypoxia inducible factor (HIF), reoxygenation, normoxia

Date Published: 8/12/2011

Citation: Wu, D., Yotnda, P. Induction and Testing of Hypoxia in Cell Culture. J. Vis. Exp. (54), e2899, doi:10.3791/2899 (2011).

\section{Abstract}

Hypoxia is defined as the reduction or lack of oxygen in organs, tissues, or cells. This decrease of oxygen tension can be due to a reduced supply in oxygen (causes include insufficient blood vessel network, defective blood vessel, and anemia) or to an increased consumption of oxygen relative to the supply (caused by a sudden higher cell proliferation rate). Hypoxia can be physiologic or pathologic such as in solid cancers $^{1-3}$, rheumatoid arthritis, atherosclerosis etc... Each tissues and cells have a different ability to adapt to this new condition. During hypoxia, hypoxia inducible factor alpha (HIF) is stabilized and regulates various genes such as those involved in angiogenesis or transport of oxygen ${ }^{4}$. The stabilization of this protein is a hallmark of hypoxia, therefore detecting HIF is routinely used to screen for hypoxia ${ }^{5-7}$.

In this article, we propose two simple methods to induce hypoxia in mammalian cell cultures and simple tests to evaluate the hypoxic status of these cells.

\section{Video Link}

The video component of this article can be found at https://www.jove.com/video/2899/

\section{Protocol}

\section{Hypoxia induced by $\mathrm{CoCl}_{2}$ solution}

Cobalt (II) Chloride hexahydrate $\left(\mathrm{CoCl}_{2} \cdot 6 \mathrm{H}_{2} \mathrm{O}, \mathrm{MW}=237.9\right)$ is a chemical inducer of hypoxia-inducible factor- $1.3^{8}$. This product is soluble in water $(100 \mathrm{mg} / \mathrm{ml})$, yielding a clear, red solution.

1. Prepare a $25 \mathrm{mM}$ stock solution in sterile dd water, (prepare immediately before use)

2. Use $\mathrm{CoCl}_{2}$ at the final concentration of $100 \mu \mathrm{M}$ in your regular cell culture media to induce hypoxia

3. Add the $\mathrm{CoCl}_{2}$ containing media to your cells and incubate the cultures for 24 hours in a conventional incubator $\left(37^{\circ} \mathrm{C} ; 5 \% \mathrm{CO}_{2}\right)$.

The above concentration works for the cell lines we have tested but each cell line should be tested at various concentrations (to establish a dose-dependent curve) as well as at various incubation times in order to limit drug related toxicity and optimize the assay.

\section{Hypoxia induced in Modular Incubator Chamber}

1. Prepare at least two identical (twin culture) cell cultures. Cell cultures can be in Flasks, plates or culture dishes. To open the chamber, first open the two white plastic clamps located on the tubes attached to the chamber (tubes used for the injection/ purging the hypoxic gas) and gently open the steel ring clamp.

2. Release the clamp. The lid and trays can now be removed.

3. Place the cell culture in the hypoxic chamber. Also place a Petri dish containing sterile water in the chamber to provide adequate humidification of the cultures.

4. Place the "twin" cell culture in normoxia as control.

5. Make sure your trays are secured and not moving, and then close the chamber with its lid. Correctly position the steel ring clamp to ensure the hermetical closure of the chamber and close it.

6. To create hypoxia, attach the tubing to a "hypoxia tank" containing a $1 \% \mathrm{O}_{2}$ gas mixture. If you have a flow meter connected to your tank your chamber will be directly connected to it (gas tank-flow meter-chamber). We use a flow meter incorporated in our regulator.

7. It is important to remove most if not all oxygen present in the chamber and in your media, to do so flush the chamber by opening the gas tank at a flow rate of 20 liters per minutes for 7-10 minutes; then quickly turn off the gas flow and completely close the chamber by closing both white clamps.

8. Return the chamber to a conventional incubator for the desired period of time. If you use large cultures, allow media in cultures to de-gas for 1- 2 hours and then repeat flush. 
The above steps are based on the constructor recommendations' (Billups-Rothenberg, Inc). Make sure you gas tank are properly secured at all time.

\section{Notes:}

- In order to eliminate the $\mathrm{O}_{2}$ contained in the media it is advised to re-gas the chamber once after 1-3hours.

- For incubation time longer than 48 hours it is also advised to re-gas the chamber.

- Oxygen sensors (electrodes/manometer) that allow measurements of the $\mathrm{O}_{2}$ contained in cells/chamber will provide a more precise measurement of the intracellular/chamber $\mathrm{O}_{2}$ contain).

- Culturing cells at various time lengths to make a time-curve would help determine the optimal time expression of HIF-1a in your particular cells.

\section{Evaluation of Hypoxia}

1. HIF-1 a detection by western blot.

1. Re-open your chamber as described in section 2.2 and immediately place your cultures on ice.

2. Lyse hypoxia treated and non-treated cells with $5 \%$ SDS solution in the plates then transfer the cell lyzate to tubes, sonicate, spindown the cell debris and collect the supernatant.

3. Measure protein concentration using BCA kit, prepare sample by adding loading buffer and heating at $95^{\circ} \mathrm{C}$ for $5 \mathrm{~min}$.

4. Electrophorese proteins on an $8 \%$ SDS-polyacrylamide gel and transfer to Nitrocellulose membranes.

5. Block the membrane in PBS containing 5\% non-fat dry milk and $0.1 \%$ Tween 20 at room temperature for 1 hour or at $4{ }^{\circ} \mathrm{C}$ overnight on shaker.

6. Immunoblot overnight with anti-HIF-1a primary monoclonal antibody $(1 / 600)$ in the same buffer at $4{ }^{\circ} \mathrm{C}$.

7. Wash 3 times in PBS containing $0.1 \%$ Tween 20 at room temperature, 5 min each time and incubate with HRP-secondary antibody $(1 / 2000)$ in PBS + $0.1 \%$ Tween 20 for $45 \mathrm{~min}$.

8. Wash 3 times in PBS containing $0.1 \%$ Tween 20 at room temperature, $5 \mathrm{~min} /$ time.

9. Use Pierce ECL kit and X-ray film to show the protein band

2. Hypoxia Responsive Element (HRE).

HIF-1a regulates numerous genes (i.e VEGF, EPO) by binding to a sequence called Hypoxia Regulating Element (HRE). Using HRE associated to a marker gene it is possible to detect HIF activity ${ }^{9}$. To use this method, first you need to transfect your cells with a HREluciferase plasmid using a transfection method adapted to your cells. For example we used Lipofectamine 2000. Cells need to be transfected at least 4 hours before to be incubated in hypoxia and normoxia. This time allows the DNA to enter the cells so that this first step is not affected by hypoxia. The luciferase signal is detected using a Luciferase Assay Kit.

1. Incubate your HRE-transfected cells in hypoxia in modular chamber or use HRE-transfected cells incubated with $\mathrm{CoCl}_{2}$, include a normoxia control.

2. After the desired incubation period, remove growth medium from cells.

3. Rinse cells in PBS, remove the PBS.

4. Dispense $400 \mu \mathrm{l} 1 \mathrm{X}$ lysis reagent into culture dish and scrape the attached cells, then transfer them to a micro tube.

5. Pellet debris by brief centrifugation.

6. Mix $20 \mu \mathrm{l}$ of cell lysates supernatant with $100 \mu \mathrm{l}$ of Luciferase Assay Reagent and measure the luminescence using a luminometer.

\section{Representative Results:}

In K562 cells (human leukemia cell line) cultured 2 days in low oxygen, compared to normoxia, hypoxia induces an increase of HIF-1a protein that was detected by western blot (Figure 1).

Using HRE-luciferase modified 293 cells (embryonic kidney cell line) cultured in hypoxia, a significant increased of HIF-1 $1 \alpha$ activity was detected in hypoxic cells (Figure 2).

\section{Hypoxia Normoxia}
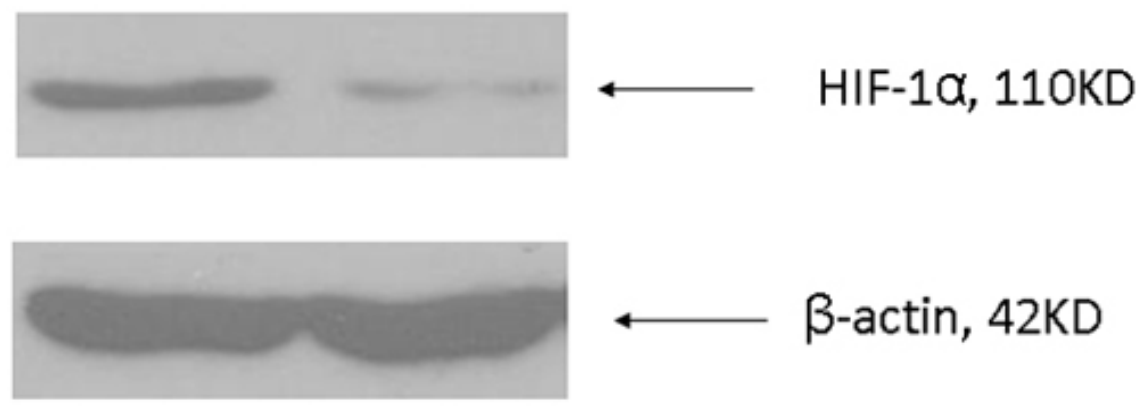
Figure 1: Increase HIF-1a in hypoxic cells. K562 cells were culture in normoxia and hypoxia (hypoxic chamber) for 48 hrs and analyzed by western blot using an antibody specific for HIF-1 $\alpha$. An antibody specific for actin was used for the loading control.

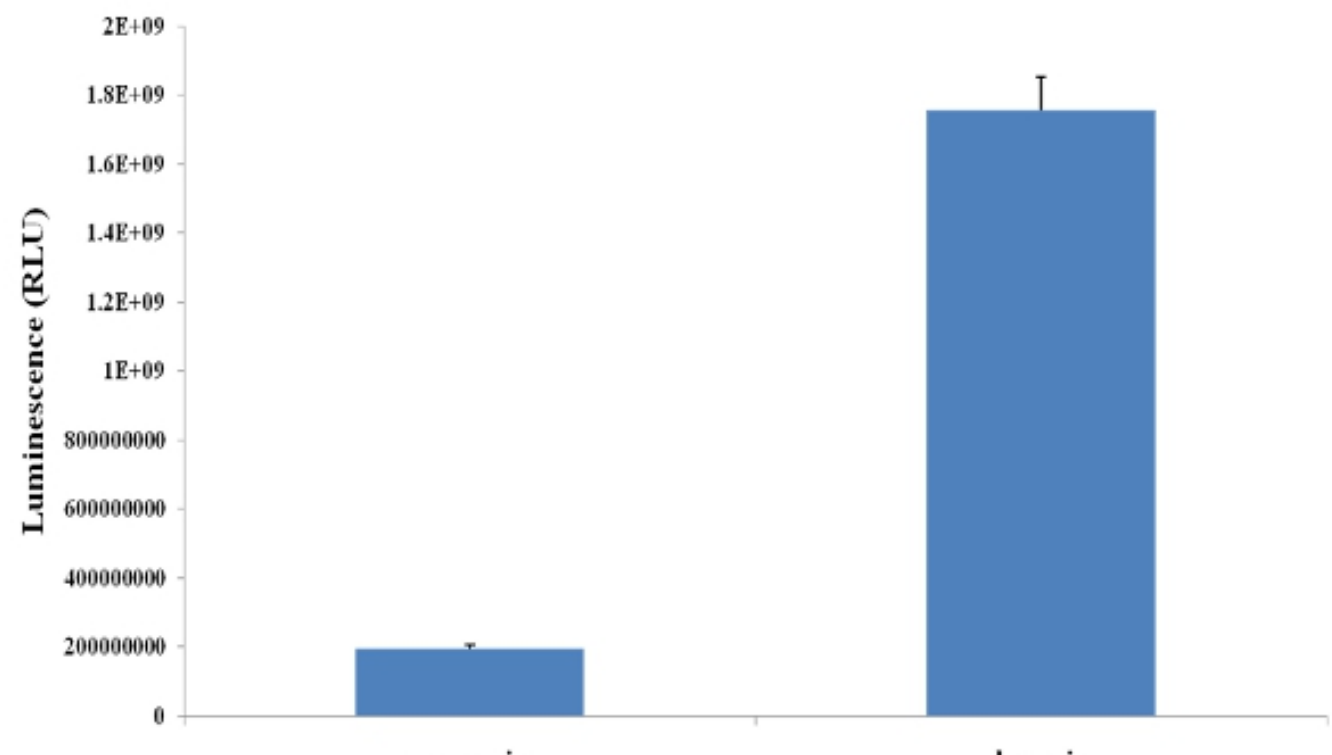

nomorxia

hypoxia

Culture conditions

Figure2: HIF-1a activity. HRE-luciferase modified 293 cells were cultured in hypoxia and normoxia for 48 hrs and then lysed to detect luciferase signal using a luciferase assay kit and a luminometer. Results are expressed as the relative luminescence unit (RLU).

\section{Discussion}

Cell proliferation and viability in hypoxic conditions vary a lot depending on the cell types. Therefore, you should adjust the cell number or the number of cultures plates you start with to make sure you will have enough cells/proteins for your experiments.

The Cobalt Chloride method has the advantage to be inexpensive and fast. This product mimics hypoxia by inducing HIF-1/3a but can also regulate other genes, make sure this product is adapted to your project by checking what other effects it could have on the function and phenotype of your particular cells independently of the "mimic-hypoxic" effect. Another drug also used to mimic hypoxia is Deferoxamine mesylate (DFO, used at $100 \mu \mathrm{M}$ final concentration). The use of these drugs allows the experimentator to open the culture plate/dish/flask many times without affecting the "hypoxic condition".

The level of oxygen contained in the gas mixture can vary depending on your experiments and cell types as hypoxia values vary depending on the tissues and cell types. Indeed, some cells are hypoxic in $5 \% \mathrm{O}_{2}$ other need less than $1 \% \mathrm{O}_{2}$ to be hypoxic. $5 \% \mathrm{CO}_{2}$ is added to the gas mixture to stabilize the $\mathrm{pH}$ of the cultures, the rest of the gas is usually Nitrogen.

Hypoxic chambers have the advantage of not using drugs that can alternate cell behavior independently of the oxygen tension. However, not all types of experimentation can be done as oxygen re-enters the chamber at each opening and thus lessens hypoxia. You should consider this factor in your experiments; hypoxia/re-oxygenation is a specific condition that can affect some cell types. An alternative is to use hypoxia workstations (connected to pre-mixed gas tanks or to gas mixing systems) or larger hypoxia incubator (hypoxia processing chamber with glove box) that allows the experimentation to change media and manipulate cells in continuous hypoxic environment. Various hypoxic chambers have been commercialized over the past decade and should be chosen according to your laboratory used, projects, space, size, and budget. Always ensure the good use and condition of your chamber to guarantee correct culture conditions. In general when using a chamber, the level of hypoxia can be modulated by selecting the various gas mixes (i.e. $1 \%, 5 \% 10 \%$ oxygen).

Regarding the detection of HIF-1a, it is important to know that some cancer cell line express HIF-1a in normoxia. It is therefore critical to use a normoxia-control to determine the basal level of HIF in these cell lines. HIF-1 $\alpha$ can also be present in normoxia in non-malignant cells following cell stimulation or stress. This could also occur if these cells are starved, make sure your cell cultures are properly feed and maintained.

\section{Disclosures}

No conflicts of interest declared. 


\section{References}

1. Swinson, D.E. \& O'Byrne, K.J. Interactions between hypoxia and epidermal growth factor receptor in non-small-cell lung cancer. Clin Lung Cancer. 7 (4), 250-256 (2006).

2. van Laarhoven, H.W., et al. Hypoxia in relation to vasculature and proliferation in liver metastases in patients with colorectal cancer. Int $J$ Radiat Oncol Biol Phys. 64 (2), 473-482 (2006).

3. Hockel, M., et al. Intratumoral pO2 predicts survival in advanced cancer of the uterine cervix. Radiother Oncol. 26 (1), 45-50 (1993).

4. Semenza, G.L. HIF-1 and human disease: one highly involved factor. Genes Dev. 14 (16), 1983-1991 (2000).

5. Semenza, G.L. Hypoxia-inducible factor 1: master regulator of O2 homeostasis. Curr Opin Genet Dev. 8 (5), $588-594$ (1998).

6. Tatum, J.L., et al. Hypoxia: importance in tumor biology, noninvasive measurement by imaging, and value of its measurement in the management of cancer therapy. Int J Radiat Biol. 82 (10), 699-757 (2006).

7. Brahimi-Horn, M.C. \& Pouyssegur, J. HIF at a glance. J Cell Sci. 122 (Pt 8), 1055-1057 (2009).

8. Piret, J.P., Mottet, D., Raes, M., \& Michiels, C. $\mathrm{CoCl}_{2}$, a chemical inducer of hypoxia-inducible factor-1, and hypoxia reduce apoptotic cell death in hepatoma cell line HepG2. Ann N Y Acad Sci. 973, 443-447 (2002).

9. Emerling, B.M., Weinberg, F., Liu, J.L., Mak, T.W., \& Chandel, N.S. PTEN regulates p300-dependent hypoxia-inducible factor 1 transcriptional activity through Forkhead transcription factor 3a (FOXO3a). Proc Natl Acad Sci U S A. 105 (7), 2622-2627 (2008). 